EXPERIMENTAL STUDY

\title{
Molecular cloning of a functional promoter of the human plakoglobin gene
}

\author{
Eyck Pötter ${ }^{1,2}$, Sabine Braun ${ }^{1}$, Ulrich Lehmann ${ }^{3}$ and Georg Brabant ${ }^{1}$ \\ ${ }^{1}$ Department of Clinical Endocrinology, ${ }^{2}$ Department of Nuclear Medicine and ${ }^{3}$ Institute of Pathology, Medizinische Hochschule, \\ D-30625 Hannover, Germany \\ (Correspondence should be addressed to G Brabant, Klinische Endokrinologie OE6820, Medizinische Hochschule Hannover, Carl-Neuberg-Str. 1, \\ D-30625 Hannover, Germany; Email: brabant.georg@mh-hannover.de)
}

\begin{abstract}
Objective: Plakoglobin $(\mathrm{Pg})$ is the only cytoplasmic protein component common to both junctional complexes mediating cell-cell adhesion, adherens junctions and desmosomes. In these complexes Pg appears to act as a linker protein anchoring transmembrane proteins of the cadherin superfamily to the actin cytoskeleton and intermediate filament system respectively. Intercellular adhesion is frequently disturbed in skin diseases and in carcinomas, enabling tumour progression and metastasis. Whereas Pg expression is lost in some thyroid tumours and carcinoma cell lines, little information on $\mathrm{Pg}$ gene regulation is currently available owing to a lack of promoter studies.

Design and methods: We have cloned and sequenced genomic DNA from a human library that resulted in $979 \mathrm{bp}$ upstream of the published Pg cDNA. The transcriptional start was mapped by rapid amplification of cDNA ends. Methylation-specific PCR of bisulfite-modified cell line DNA was applied to probe the methylation status of a promoter-associated CpG island. Reporter-gene constructs of various promoter fragments were transiently transfected in thyroid carcinoma cell lines and their activities were determined by luciferase measurements.

Results and conclusions: A $1 \mathrm{~kb}$ DNA fragment harbouring a functional promoter of the human $\mathrm{Pg}$ gene was cloned and characterized. The sequence lacks a canonical TATA box, but contains putative CCAAT boxes as well as various putative binding sites for transcription factors, among them SP1 and AP2, proximal to the transcriptional start. Considerable promoter activity was found in thyroid cell lines and deletion analysis indicated that a $300 \mathrm{bp}$ region proximal to the $5^{\prime}$-untranslated region of the mRNA represents the minimal promoter of the human Pg gene. As cells lacking endogenous Pg expression were found to contain methylated CpG dinucleotides in a CpG island located around the transcriptional start site, it is suggested that epigenetic mechanisms such as DNA methylation contribute to dysregulated Pg expression.
\end{abstract}

European Journal of Endocrinology 145 625-633

\section{Introduction}

Plakoglobin (Pg), also termed $\gamma$-catenin, forms with its closest relatives $\beta$-catenin and Drosophila segment polarity protein, armadillo, a subgroup of the large armadillo protein family that share a 42 -amino-acid motif repeated several times (1). As a major cytoplasmic protein, Pg occurs in a soluble and a membraneassociated form, where it was first identified in both adhesive intercellular junctions, desmosomes and adherens junctions $(2,3)$. In adherens junctions, Pg and $\beta$ catenin form mutually exclusive complexes with the cytoplasmic tail of E-cadherin and provide a link to $\alpha$-catenin that, in turn, establishes a connection to actin, which is a prerequisite for stable cadherin-mediated cell adhesion to occur (4). Pg, unlike the other catenins, is in addition a major component of the desmosomal plaque
(2) where it binds to the desmosomal cadherins, desmogleins and desmocollins, to anchor them through desmoplakins to the intermediate filament (5). The crucial roles of $\mathrm{Pg}$ for protein sorting, desmosomal plaque assembly and intermediate filament anchorage have clearly been demonstrated with Pg null-mutant mouse embryos that die early during development as a result of severe heart defects $(6,7)$. Recently, a homozygous mutation of the Pg gene leading to a truncation of the protein has been identified in patients suffering from Naxos disease, an autosomal recessive form of arrhythmogenic right ventricular cardiomyopathy (8). Even though Pg is an important common component of both cell-cell adhesion complexes, which are essential for tissue integrity and are frequently negatively affected in invasive and metastatic carcinomas (4), the gene structure has only very recently been 
published (9), and factors regulating its promoter are still unknown. Previously, we and others observed a decreased expression of $\mathrm{Pg}$ in thyroid carcinomas and cell lines, which could partially be restored by inhibition of DNA methylation (10-14). To better understand regulation of the gene encoding $\mathrm{Pg}$, we cloned the $5^{\prime}$ flanking region of the human Pg gene, characterized its activity by transient transfection analysis in thyroid carcinoma cell lines and investigated the DNA methylation status of an associated CpG island.

\section{Materials and methods}

\section{Cloning and sequence analysis}

To clone the promoter region of the human Pg gene, five human DNA libraries of the Genome Walker kit (Clontech, Heidelberg, Germany) were used. Each library consists of uncloned, restriction enzymedigested, adaptor-ligated genomic DNA fragments. PCR was performed with each of the libraries with the adaptor-specific primer AP1 and the Pg-specific reverse primer 1 (5'-GGTGGGAGCCGGCGCGGACAGC$3^{\prime}$; start at position 69 in $\mathrm{Pg}$ cDNA, accession no. M23410). Following dilution, the products were used as templates for a second PCR with nested adaptor primer AP2 and Pg-specific reverse primer $2\left(5^{\prime}-\right.$ GAACTGAGCTCGGCGCGGTCGGG-3'; start at position 47 in $\mathrm{Pg}$ cDNA). Amplification conditions were as described in the manufacturers protocol and Tth polymerase mixes as well as other reagent components were also obtained from Clontech. An amplified DNA fragment of $0.7 \mathrm{kbp}$ obtained from the ScaI library was cloned in the T/A cloning vector pCRII (Invitrogen, Leek, The Netherlands) and designated pPG1.

DNA sequencing was performed on both strands using the Thermo sequenase radiolabeled terminator cycle sequencing kit (Amersham Life Sciences, Freiburg, Germany). To further extend the obtained sequence a second PCR walk was performed as before but using primer pairs AP1/Pg3 (5'-ACAGACGCCTTCACCGGCCAGCCAAC-3') and AP2/Pg4 (5'-TCAGCGTCAGGCATGATGCTTCTTTGGGCT- ${ }^{\prime}$ ) in the first and second PCR respectively, whereby the Pg-specific primers were derived from the pPG1-upstream sequence. As before, the product was cloned to give pPG2, subsequently sequenced, and the complete sequence assembled.

Nucleotide homology searches were performed using the Fasta3 program (15) (http://www.ebi.ac.uk/fasta3) and searches for potential transcription factor sites were carried out with the programs Mathinspector 2.2 (16) and FunsiteP (17) (both at http://transfac.gbf.de/ transfac/programs) using the TRANSFAC database (18). The programs Grail 1.3 (http://compbio.ornl. gov/grail-1.3) and CpGplot/report (http://www.ebi. ac.uk/emboss/cpgplot) were used for CpG island prediction.

\section{5'-Rapid amplification of cDNA ends}

To characterize the transcriptional start an established $5^{\prime}$-rapid amplification of cDNA ends (5'-RACE) procedure (19) was applied using a commercial kit (Gibco Life Technologies, Eggenstein, Germany) according to the manufacturers instructions. Briefly, $3 \mu \mathrm{g}$ total RNA isolated from $8505 \mathrm{C}$ cells was reverse transcribed by Superscript RT II (Gibco Life Technologies) in separate reactions using the Pg-specific antisense primers 361R (5'-CTGGCTGTTGTGGACATCTG-3') or 203R (5'-CGAGTGGATACCCGAGTCGTA-3'). The cDNAs were treated with RNase $\mathrm{H}$, purified and dC-tailed in a terminal transferase reaction. Primary PCR was performed with abridged anchor primer and the Pg-specific nested primers 203R or 174R (5-TCTGCTGCCACTCAGTCACCT-3'). Following secondary PCR using universal abridged anchor primer and Pg-specific nested primers 174R or 141R (5-CCATCAGGTTCATCACCTCCAT-3') the respective PCR products were subcloned in pCR2.1 (Invitrogen) and the corresponding nucleotide sequences of a total of 15 clones were determined by didesoxy sequencing using primer 141R and universal M13 primers.

\section{Reporter-gene constructs}

For in vitro transient expression assays a number of fragments were subcloned into the SmaI site of the promoter- and enhancerless luciferase (LUC) expression vector pGL3Basic (Promega, Mannheim, Germany).

In brief, the cloned fragment was cut from pPG1 with EcoRI, the ends filled in with Klenow DNA polymerase and the resulting fragment cloned in both orientations in the SmaI site in front of the LUC gene of pGL3Basic yielding constructs pGLPg1 and pGLPg2 (reverse orientation). Using unique SmaI sites in the fragment and the adaptor, pGLPg1 and pGLPg2 were digested with SmaI, the inserts removed and the vectors religated to give the deletion constructs pGLPg 3 and pGLPg4 (reverse orientation). The dissected SmaI fragment of this step $(\sim 400 \mathrm{bp})$ distal to the coding region was subcloned in SmaI-digested pGL3Basic, yielding the constructs pGLPg 5 and pGLPg6 (reverse orientation). The EcoRI fragment isolated from pPG1 was further cut with BspMI. Products of $0.24 \mathrm{kbp}$ and $0.44 \mathrm{bp}$ were isolated, their ends filled and cloned in SmaI-digested pGL3Basic, and named pGLPg7 and pPLPg9 respectively. The corresponding constructs with DNA fragments in reverse orientation were termed pPGLPg8 and pGLPg10 respectively. Two DNA fragments ending proximal to the $5^{\prime}$-end of the published $\mathrm{Pg}$ cDNA were produced by PCR using pPG1 as template and a common reverse primer $5^{\prime}$-AAGGCAGCAACTCAGTAACG-3' in combination with forward primers $5^{\prime}$-GTTAGGATGAGACCTCAAG-3' and $5^{\prime}$ ACGGGACAGTCAGGCGAGATA-3'. Both products were cloned in pCR2.1 (Invitrogen, Karlsruhe, Germany) 
using a T/A cloning kit and as before their respective EcoRI fragments were filled in and subcloned into the SmaI site of pGL3Basic to give transfection constructs pGLPg11 and pGLPg12 respectively. The orientations of cloned fragments were checked by restriction enzyme digestions and all constructs were sequenced.

A complete fragment of approximately $1 \mathrm{kbp}$ consisting of PG1 and PG2 was produced by PCR using human genomic DNA and cloned in pCR2.1 (Invitrogen). Thereof, an EcoRV/SmaI-fragment was isolated harbouring PG2 and a part of PG1 and subcloned in the SmaI site of pGLPg 5 to yield pGLPg0. Three pGLPg0 clones were sequenced and used for transfections.

\section{Cell culture, transient transfections and promoter activity measurements}

Human thyroid carcinoma cell lines FTC-133 (20) (a generous gift from P. E. Goretzki, Düsseldorf, FRG), C643 (21) (generously supplied by N. E. Heldin, Uppsala, Sweden) and TPC-1 (22) (from S. Jhiang, Columbus, OH, USA) were cultured in DMEM/HamF12 (1:1) supplemented with $10 \%$ foetal bovine serum, penicillin $(100 \mathrm{IU} / \mathrm{ml})$ and streptomycin $(100 \mu \mathrm{g} / \mathrm{ml})$ at $37{ }^{\circ} \mathrm{C}$ in a humidified atmosphere with $5 \% \mathrm{CO}_{2}$. The human thyroid carcinoma cell line 8505C (23) (DSMZ, Braunschweig, Germany) was grown in RPMI 1640 with supplementations as above. Cells $\left(2 \times 10^{5}\right)$ were plated in six-well plates 1 day before transfection. Transfections mediated by Fugene 6 (Roche, Mannheim, Germany) were carried out according to the manufacturers protocol using $1.5 \mu \mathrm{g}$ of each promoter construct. To correct for transfection efficiency differences $1.5 \mu \mathrm{g} \beta$-galactosidase expression plasmid pSV $\beta$ Gal was cotransfected. The vector pGL3Ctrl (Promega, Mannheim, Germany) served as a positive control in parallel transfections conferring strong LUC expression driven by the SV40 promoter. Enzyme activities were determined $48 \mathrm{~h}$ post-transfection using a LUC assay kit and a $\beta$-galactosidase assay kit (both from Promega). All LUC activities were normalized to $\beta$-galactosidase activity and were given relative to the basal activity of empty pGL3Basic, which was set to unity. Measurements were performed in duplicate and repeated in 3-8 independent experiments. The data shown represent mean values (士 s.E.M).

\section{Methylation analysis}

To detect DNA hypermethylation of the Pg gene the methylation-specific PCR protocol was used (24). Briefly, genomic DNA of cell lines was isolated using a commercial kit (Qiagen, Hilden, FRG) and $1 \mu \mathrm{g}$ was treated with sodium bisulfite as described (25). The modified DNA was subjected to PCR in separate reactions using the primer pairs PG-M (5'-TAGTCGTCGTTCGATCGCGTC-3' and $5^{\prime}$-AACCGAATCGAAATCGAACCG-3') and PG-U

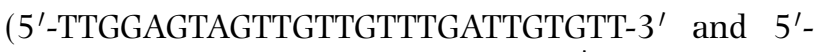
CAAACCAAATCAAAATCAAACCAA-3') designed to distinguish methylated from unmethylated DNA. The PCR mixtures contained $1 \times$ PCR buffer $(20 \mathrm{mM}$ Tris$\mathrm{HCl} \mathrm{pH} \mathrm{8.4,} 50 \mathrm{mM} \mathrm{KCl}), 200 \mu \mathrm{M}$ dNTPs, $1.5 \mathrm{mM}$ $\mathrm{MgCl}_{2}, 10$ pmol each primer per reaction, $0.5 \mathrm{U}$ PlatinumTaq DNA polymerase (Gibco Life Technologies) and $50 \mathrm{ng}$ template in a final volume of $25 \mu \mathrm{l}$. Amplification was carried out after an initial enzyme activation step $\left(5 \mathrm{~min}\right.$ at $\left.95^{\circ} \mathrm{C}\right)$ for 40 cycles $(30 \mathrm{~s}$ at $95^{\circ} \mathrm{C}, 45 \mathrm{sec}$ annealing, $30 \mathrm{~s}$ at $72{ }^{\circ} \mathrm{C}$ ), followed by a final extension $\left(5 \mathrm{~min}\right.$ at $\left.72{ }^{\circ} \mathrm{C}\right)$. Annealing temperatures of $62{ }^{\circ} \mathrm{C}$ and $60{ }^{\circ} \mathrm{C}$ were used for PG-M and PG-U reactions respectively. The PCR products were resolved on a $6 \%$ polyacrylamide gel, stained by ethidium bromide and visualized under ultraviolet illumination. Expected PCR product sizes are 76 bp (position +30 to +105; cf. Fig. 1) in the case of presence of methylated CpGs in the $\mathrm{Pg}$ gene region covered by the PG-M primers or 84 bp (position +24 to +107 ; cf. Fig. 1 ) in the case of presence of unmethylated $\mathrm{CpG}$ dinucleotides using the PG-U primers.

\section{Protein extraction and Western blotting}

Cell lines were treated in parallel with and without 5-Aza-2'-deoxycytidine (AzaC; Sigma Chemicals, Taufkirchen, Germany) at a final concentration of $1 \mu \mathrm{M}$ in growth medium for 4-5 days. For total protein extract preparations cells were briefly washed with phopshate-buffered saline (PBS; $150 \mathrm{mM} \mathrm{NaCl}, 10 \mathrm{mM}$ sodium phosphate $\mathrm{pH}$ 7.4) and lysed by addition of hot Laemmli sample buffer (26). The lysates were briefly sonicated, heated $\left(5 \mathrm{~min}, 95^{\circ} \mathrm{C}\right)$ and centrifuged $(10 \mathrm{~min} 14000 \times \mathrm{g})$ to remove insoluble material. The resulting supernatants were used for Western blotting. Protein contents were estimated according to Lowry (27) following trichloroacetic acid precipitation. Equal amounts of protein $(10 \mu \mathrm{g} / \mathrm{lane})$ were separated by $7.5 \%$ SDS-PAGE (26) and transferred electrophoretically to polyvinylidene difluoride membranes (28). After blocking with $5 \%$ non-fat dry milk in $0.1 \%$ Tween/PBS the membranes were incubated overnight at $4{ }^{\circ} \mathrm{C}$ with mouse monoclonal antibodies against $\beta$-catenin or $\mathrm{Pg}$ (Transduction Lab, Lexington, KY, USA). Following incubation with secondary anti-mouse IgG conjugated to either horseradish peroxidase or alkaline phosphatase bands were detected by chemoluminescence using an ECL kit (Amersham) or CSPD plus Emerald-Enhancer (Oncogene Science, San Diego, CA, USA) respectively, according to the manufacturers' protocols.

\section{Results}

A PCR-based approach was used to clone the $5^{\prime}$ flanking region of the human $\mathrm{Pg}$ gene. The assembled sequence consists of 1026 nucleotides (Fig. 1) and includes at the $3^{\prime}$-end a stretch of 46 nucleotides, 
PEA3

\begin{tabular}{|c|c|c|c|c|c|c|}
\hline-965 & CTGGTTTGGT & & & & & \\
\hline-905 & TAGTTTTGTG & ACTTCTCTGA & ACTTCGGTTT & СТTСАТСТTT & ACAATGAGGG & TCGTTTTCTC \\
\hline-845 & ATCCTAACTA & TTTTTCAGAG & CTGTCACAAT & AATTAAAAAA & AAACATACCG & TTAАТTTAAA \\
\hline 785 & TTTCTAACCT & TTAGCAGTTT & CTGAGTGCTT & TCACAAACCT & GACCTCATTT & $\triangle A T C C C C A C A$ \\
\hline 725 & TACTCCAGTG & AGGTAGATAT & $\begin{array}{c}\text { GGCTAATGTA } \\
\text { NKX2.5 }\end{array}$ & TCCAGTTIAC & GAAGAGGAG & CAGGGTG \\
\hline 665 & AAGTAACTTG & CCTAAAATCA & TACCAAGTGG & $\begin{array}{r}\text { GAGAAGACCA } \\
\text { AP2 }\end{array}$ & AACCTGGCCT & СТААТТСТА \\
\hline 605 & AATCCCAGGA & GTACTCCATC & TTTCGGGAAA & AAAATCCCAC & CCCAGCACAA & AGCCTP \\
\hline .545 & ATGCTATACA & AATATGTGAT & TACTACTTTG & GGGCAAGGAT & GAATAAGCCC & AAGAA \\
\hline 485 & CATGCCTGAC & GCTGAGTTGG & CTGGCCGGTG & AAGGCGTCTG & $\begin{array}{r}\text { TCCCTTCCCT } \\
\mathrm{My}\end{array}$ & $\begin{array}{l}\text { TGGTATCCCT } \\
\text { yoD }\end{array}$ \\
\hline 425 & ATGACTTACC & TGTTGGACAG & GTAGGGGGAA & $\begin{array}{c}\text { GGGGAGAGTA } \\
\text { CCAAT }\end{array}$ & ATGAGTCTCA & CCTGCT \\
\hline-365 & GCAAGGGTGG & $\begin{array}{l}\text { GGCAAGACAC } \\
\text { CСAAT }\end{array}$ & ACCCCATCCC & TTCCATTGGT & $\begin{array}{l}\text { ТTТТТССТТА } \\
\text { ССААТ }\end{array}$ & GTCTTAC \\
\hline-305 & CAGAGCCTTG & TCCAATCAGG & AGGAAGTAAC & TTTCTATCTG & $\begin{array}{c}\text { CCAATAGATG } \\
\text { AP2 }\end{array}$ & $\begin{array}{l}\text { CAATGTTAGG } \\
\text { CCAAT }\end{array}$ \\
\hline-245 & ATGAGACCTC & AAGTTAGAGT & CCATCCCTAG & $\begin{array}{r}\text { AGCCGACTGG } \\
\text { SP }\end{array}$ & $\frac{\text { CAGTCCCCGG }}{\operatorname{SP} 1}$ & GGCCAATGGC \\
\hline-185 & AAGCGGATAA & ACAGAGGCGG & CCGTGGAAGA & GGACTGGAGG & CGAGGCTCCG & $\frac{\text { CCCCTCCACG }}{\text { AP2 }}$ \\
\hline 20 & GGACAGTCAG & GCGAGATAGC & CAGTGAGCTC & GCACCAGAGG & GTGGGCGTCT & CCCCCAGGGG \\
\hline & CGGAGCTTCG & AGGTGGCGAG & GGGCGTGGCT & TGGCTGTCAG & GTCTCTTCGC & CTTTTGTTCG \\
\hline-5 & $\begin{array}{l}\text { GTTACTGAGT } \\
\text { CAGTTC }\end{array}$ & TGCTGCC & GCCAGAGTCC & $G G A G$ & CCGCCCGACC & GCGCCGAGCT \\
\hline
\end{tabular}

Figure 1 Nucleotide sequence of the $5^{\prime}$-flanking region of the human plakoglobin gene. Asterisks mark both major transcriptional positions mapped by $5^{\prime}$-RACE and numbering refers to the most distal transcriptional start point $(+1)$. The sequence in italics represents the overlap with the published human plakoglobin CDNA (3), which starts at -119 relative to the translational start codon. Putative CCAAT boxes are shown underlined and putative regulatory elements are indicated in bold letters above the underlined sequence.

which are identical to the start region of the corresponding human Pg cDNA (positions 2-47; accession no. M23410), published previously (3). This overlap confirms that the amplified DNA region represents the $5^{\prime}$-flanking region of the Pg gene. Thus we extended the $5^{\prime}$-flanking region of this gene by $979 \mathrm{bp}$. The sequence of the $5^{\prime}$ - flanking region of the human Pg gene (Fig. 1) has been deposited with the EMBL Nucleotide Sequence Databases (accession no. AJ276892). Whereas the overall GC-content of the sequence is $50 \%$, the GC-content of $300 \mathrm{bp}$ located at the $3^{\prime}$-end is considerably higher $(66 \%)$ and this short segment notably harbours 24 out of a total $31 \mathrm{CpG}$ dinucleotides. According to established criteria (29) computer analysis by the CpGplot program predicts one $\mathrm{CpG}$ island of at least $330 \mathrm{bp}$ that starts at position -219 (Fig. 1) and extends into exon 1 of the Pg gene. The promoter sequence lacks a canonical TATA box, but contains four putative CCAAT boxes, of which the most downstream CCAAT box located 200 bp proximal to the start of the corresponding Pg cDNA shows the least differences in the flanking nucleotides to published
CCAAT consensus sequences $(30,31)$. Computer searches for putative regulatory regions resulted in a number of probable transcription factor binding sites, most of them localize to the second half of the sequence. Putative regulatory factors include stimulatory protein-1 (SP1), activator protein-2 (AP2), PEA3, MyoD and Nkx2.5 (Fig. 1).

The transcriptional site was mapped by the $5^{\prime}$-RACE procedure (19) using RNA isolated from $8505 \mathrm{C}$, a human anaplastic thyroid carcinoma cell line (23), and different combinations of Pg mRNA-specific primers. Four of 15 sequenced clones extended the Pg cDNA sequence by 14 nucleotides (designated position +1 in Fig. 1), four clones started at position +2 , and six started in pos. +15 , the published 5'-end of Pg cDNA (3), with the remaining clones being scattered between these regions or were shorter probably due to degradation. On the basis of these results, we assigned two major transcriptional start points at positions $+1 /+2$ and +15 (cf. Fig. 1).

To study the promoter activity the complete $1026 \mathrm{bp}$ fragment as well as seven deletion fragments were 
A

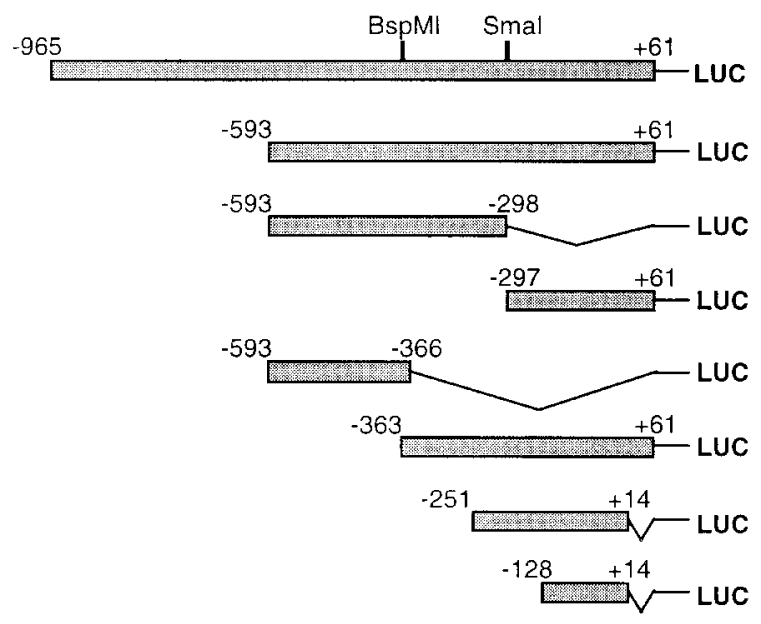

B

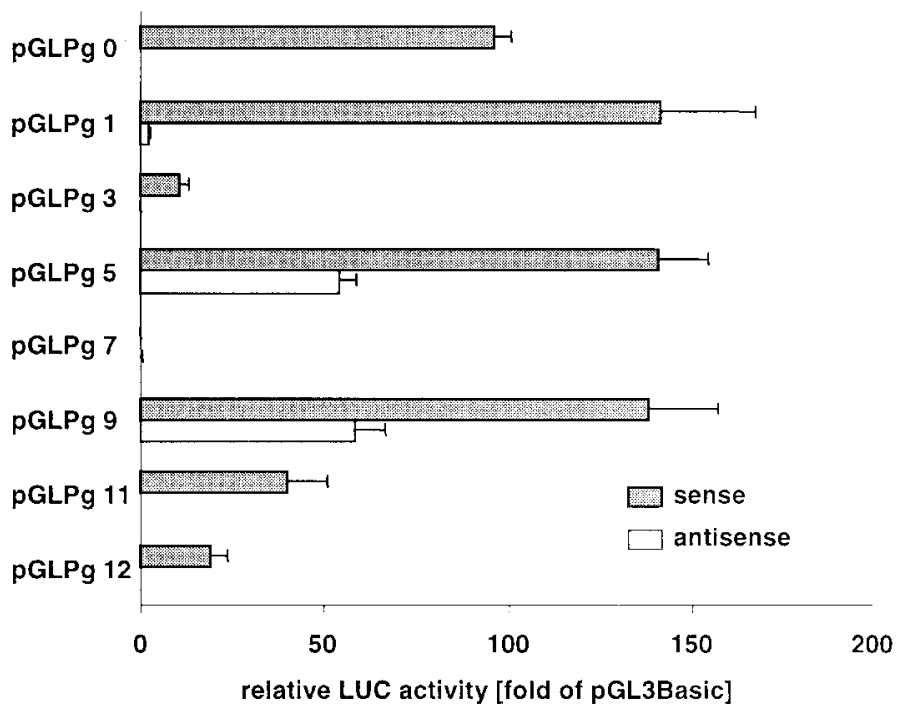

C

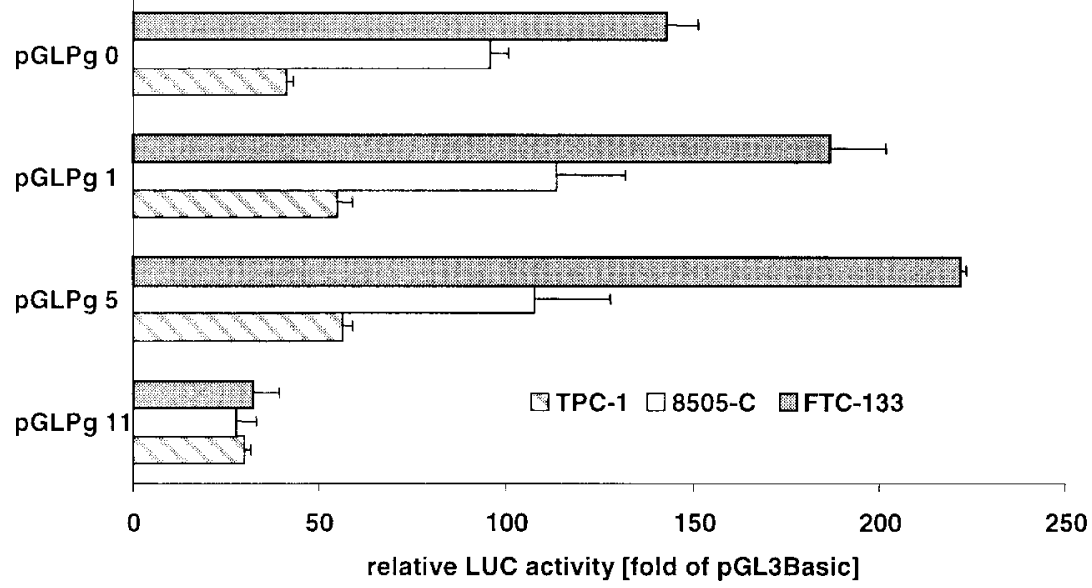

Figure 2 Promoter activity measurements. (A) Schematic of reporter-gene constructs used in transient transfection assays. Various fragments of the $5^{\prime}$-flanking region of the human Pg gene were fused in front of the LUC gene in the pGL3Basic vector. Numbering of nucleotides is given as in Fig. 1. (B) Functional analysis of Pg promoter-LUC constructs in 8505C cells. Cells were transiently transfected with $1.5 \mu \mathrm{g}$ pGL3Basic containing fragments of the $5^{\prime}$-flanking region of the human Pg gene in front of the LUC gene, or $1.5 \mu \mathrm{g}$ empty pGL3Basic, and $1.5 \mu \mathrm{g}$ pSV $\beta$ Gal vector respectively. Expression vectors carrying the respective fragment in antisense orientation were available for pGLPg-constructs 1, 3, 5, 7 and 9. All LUC activities were measured $48 \mathrm{~h}$ post-transfection, and were normalized to the $\beta$-galactosidase activity. The LUC activity of empty pGL3Basic was set to unity and the activity of each promoter construct was expressed as a fold increase over that value. (C) Cell lines FTC-133, 8505C and TPC-1 were transiently transfected with empty pGL3Basic vector or Pg-LUC constructs pGLPg0, 1, 5 or 11 in combination with pSV $\beta$ Gal and activity measurements were performed as in Fig. 2B.

cloned into the promoterless LUC expression vector pGL3Basic. The reporter-gene vectors (cf. Fig. 2A) were used for transient transfections of $8505 \mathrm{C}$ cells, and the transcriptional activation was determined by LUC activity measurements. As shown in Fig. 2B, the complete sequence (pGLPg0) was able to efficiently drive LUC expression, about 96-fold compared with the empty pGL3Basic vector. Comparison of the data for the full-length construct (pGLPgO) and the $5^{\prime}$-deletion constructs (pGLPg1, 5 and 9) indicates the presence of a silencing element in the first 360 nucleotides (positions -965 to -594 ). Constructs lacking this $5^{\prime}$ region, but cloned in reverse orientation displayed either no or reduced stimulation of LUC expression (Fig. 2B). These results thus confirmed that the DNA region -593 to +61 functions as a promoter element. The central third of the complete sequence (nucleotides -593 to about -220; pGLPg3, pGLPg7) did not 

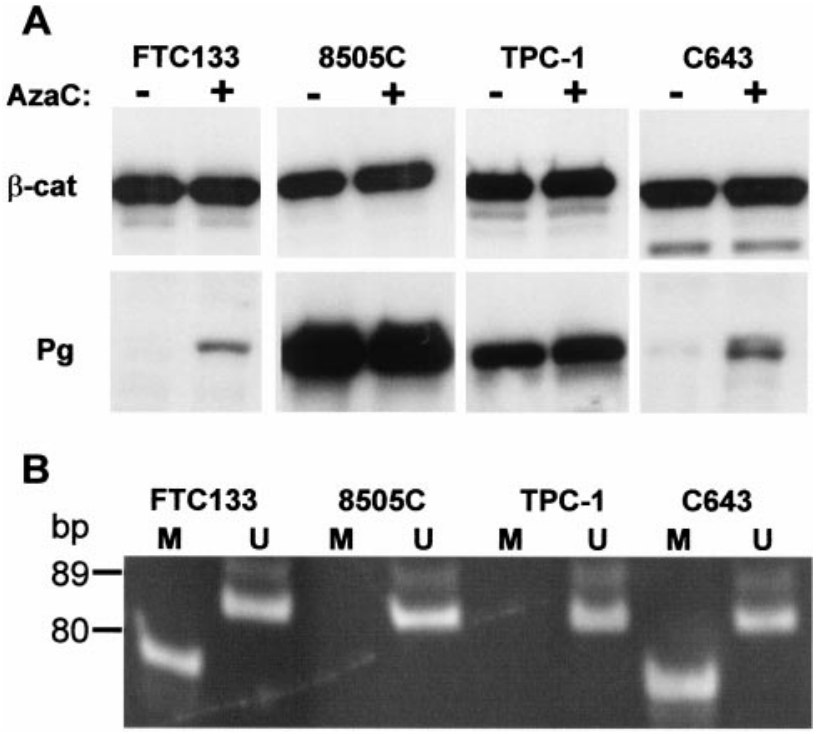

Figure 3 Protein expression and DNA-methylation status. (A) Cells were treated with (+) and without $(-) 1 \mu \mathrm{M} \mathrm{AzaC}$ for $4-5$ days. Total protein extracts containing equal amounts of proteins of treated/untreated cell lines were analyzed by Western blotting using antibodies directed against $\beta$-catenin ( $\beta$-cat) and Pg. Note that the applied protein amounts for $8505 \mathrm{Cs}$ used for $\mathrm{Pg}$ blotting had to be reduced to allow comparison. (B) Methylation-specific PCR. Genomic DNA of cell lines was extracted, modified by bisulfite treatment and subjected to PCR with primer pairs PG-U $(\mathrm{U})$ and PG-M (M) specific for unmethylated and methylated alleles of a $\mathrm{Pg}$ promoter-associated $\mathrm{CpG}$ island respectively. PCR products were analysed by nondenaturing 6\% PAGE. Expected product sizes were 76 bp and 84 bp for PG-M and PG$\mathrm{U}$ primers respectively. The numbers on the left indicate the size of markers (bp).

stimulate LUC transcription efficiently when used without the last part indicating essential functions of the latter region. The high LUC activity (about 140-fold when compared with basal activity of pGL3Basic) measured with fragments harbouring the 3'-end regions (pGLPg9, pGLPg5) is consistent with this interpretation. Thus, most of the promoter activity can be attributed exclusively to the last third of the sequence (nucleotides about -220 to +61 ). Further $5^{\prime}$ deletions led to a progressive decrease of LUC activity (pGLPg11, pGLPg12). Notably, only in these two constructs have the 46 nucleotides corresponding to the 5'-UTR of the Pg mRNA also been deleted. Obviously this GC-rich region positively regulates transcription, as indicated by the threefold lower stimulation of LUC expression by construct pGLPg11 when compared with the otherwise similar construct, pGLPg 5 (Fig. 2B). Further deletion of regions harbouring the most downstream CCAAT box and GC-rich regions, probably representing binding sites for SP1 and AP2, considerably decreased LUC expression (pGLPG12).

In order to better understand the variable downregulation of Pg expression in different thyroid tumours and cell lines reported previously (10-14), we used four constructs (pGLPg0, 1, 5 and 11) for transient transfections of three human thyroid carcinoma cell lines (FTC-133, TPC-1 and 8505C) which endogenously express very low, medium and high levels of $\mathrm{Pg}$ (Fig. 3A) respectively and were derived from follicular, papillary and anaplastic thyroid tumours respectively $(20,22,23)$. The overall activity patterns of transfected constructs were comparable in the three cell lines (Fig. 2C). Again a lower LUC expression of the the fulllenght construct (pGLPg0) compared with the 5'deletion constructs lacking the first 360 nucleotides (pGLPg1 and 5) may be attributed to the presence of a silencing element in that region. As well, the strongly decreased LUC activity of construct pGLPg11 might again be indicative of a regulatory role of the $5^{\prime}$-UTR of $\mathrm{Pg}$. The results with all constructs also indicate, that a loss of Pg expression in FTC-133 and TPC-1 is not caused by the lack of essential transcription factors, as transfectants displayed considerable LUC activity (TPC-1) compared with transfected $8505 \mathrm{C}$, or even approximately twofold higher LUC activity in the case of FTC133, that has almost completely lost Pg expression.

To identify an underlying mechanism for loss of $\mathrm{Pg}$, cell lines including $\mathrm{C643}$, an anaplastic thyroid carcinoma cell (21), were treated with the wellknown cytosine analog $\mathrm{AzaC}$, which after being incorporated into DNA inhibits DNA (cytosine-5)methyltransferase at the target site for DNA methylation, CpG dinucleotides, and thereby indirectly leads to demethylation of methylated $\mathrm{CpG}$ islands (32). A partial restoration of Pg expression was detectable in FTC133 and C643 by Western blotting (Fig. 3A) as well as by Northern blotting (data not shown). The AzaCmediated increase of Pg gene expression appears to be specific as the amounts of $\beta$-catenin (Fig. 3A), $\alpha$ catenin and $\mathrm{p} 120^{\mathrm{ctn}}$ (data not shown) remain unaffected. Therefore, Pg down-regulation might result directly from aberrant DNA hypermethylation of its gene. To investigate this possibility, genomic DNA of cell lines was modified by bisulfite treatment, which converts unmethylated cytosine residues to uracil without affecting 5-Methylcytosine residues, and subsequently subjected to PCR with primer pairs PG-M and PG-U intended to discriminate the methylation status of $\mathrm{CpG}$ dinucleotides located to the $\mathrm{CpG}$ island extending into exon 1. As shown in Fig. 3B, 8505C and TPC-1, which both were AzaC-unresponsive and endogenously express Pg, contain only unmethylated alleles. By contrast, the Pg-negative and AzaC-responsive FTC133 and C643 clearly displayed CpG methylation in addition to unmethylated alleles.

\section{Discussion}

The present study reports the cloning and characterization of a $1 \mathrm{~kb}$ DNA region representing the human Pg 
promoter region, which to our knowledge has not yet been published. In previous investigations the human Pg cDNA was cloned (3), and the human Pg gene was mapped to chromosome $17 \mathrm{q} 12-\mathrm{q} 22$ in proximity to the breast cancer susceptibility gene 1, BRCA1 (33). Very recently, when this work was finished, the complete genomic organization of the human $\mathrm{Pg}$ gene has been reported showing that the $\mathrm{Pg}$ gene probably consists of 13 exons covering a $17 \mathrm{~kb}$-long DNA region (9). The start region of the sequence obtained (accession no. AF233882) is identical with our nucleotide sequence, but did not cover the first 152 nucleotides, as reported here. In addition, a working draft sequence generated from a chromosome 17-derived clone in the course of the human genome project became accessible in the EMBL HTG nucleotide database (accession no. AC012192) which at present (version 14) consists of $183 \mathrm{~kb}$ DNA in 15 unordered contigs; a part of contig 45 was found to be identical $(99.8 \%)$ to the DNA sequence reported here and extends our sequence in both directions. In agreement with our data, both sequences show the same nucleotide difference at the start position of the published Pg cDNA sequence (pos. +15 in Fig. 1; G instead of a $\mathrm{C}$ ).

These data clearly confirm that we achieved the cloning of a part of a functional human Pg promoter. In contrast to the gene encoding the related $\beta$-catenin (34) no obvious TATA box is present, but the cloned region includes in the $3^{\prime}$-half CCAAT boxes, GC-rich regions, the presence of putative transcription factor binding sites, and a high frequency of CpG dinucleotides located to a $\mathrm{CpG}$ island, which in combination are characteristic features commonly found in many promoters of housekeeping and tissue-specific genes (29-31).

Two closely neighboured major transcriptional start sites of the Pg gene were mapped by $5^{\prime}$-RACE their positions are compatible with the results of the transfection experiments (cf. Fig. 2) and the location of the most proximal CCAAT box (position -193, cf. Fig. 1), although the latter is more frequently found at $\sim$ position -70 in promoters lacking TATA boxes (30). Transfection of thyroid cell lines with Pg reporter-gene constructs results in a strong transcriptional activation that depends both on orientation and size of the respective fragments. Although a direct participation of trans-acting factors remains to be shown, the major CCAAT box-binding protein, NF-Y (30), as well as the general transcriptional activators, AP2 and SP1, binding to GC-rich regions following the proximal CCAAT box might contribute to the transcriptional activation observed.

Because of its comparable roles in adherens junctions and desmosomes Pg is commonly found in epithelia of various tissues but its expression is not restricted to them (5). Essential functions of $\mathrm{Pg}$ for heart development which can not be compensated for by its homologoue, $\beta$-catenin have been revealed in studies with knockout mice $(6,7)$. Interestingly, a sequence element (position -645; cf. Fig. 1) could represent a binding site for a heart-specific transcription factor, termed Nkx2.5 (also called Csx), a homeobox-containing gene expressed in cardiocytes and their progenitors and found to be essential for cardiac development (35, 36). As two additional Nkx2.5 binding sites are present in a region located further upstream, covered by the sequence AC012192 (see above), it is tempting to speculate that the $\mathrm{Pg}$ gene represents a downstream target for Nkx2.5 in the heart.

Loss of cadherin/catenin-dependent intercellular adhesion is found frequently in many carcinomas and represents one key step in tumour progression and metastasis (4). Pg as an essential cytoplasmic anchoring protein for classic cadherins (e.g. E-cadherin) in adherens junctions and demosomal cadherins (desmogleins and desmocollins) in desmosomes participates in these processes. Reduced Pg expression correlates with malignant transformation in certain tumour cell lines $(10,12,37,38)$ and $\mathrm{Pg}$ overexpression can decrease the tumorigenicity and proliferation of transformed cells $(39,40)$. This might also relate to the participation of $\mathrm{Pg}$ and $\beta$-catenin in the wnt signal transduction pathway that is frequently dysregulated in certain carcinomas (41). Whereas the Pg-related $\beta$-catenin represents a potential oncogene, $\mathrm{Pg}$ appears to play a tumour suppressor role $(33,39,40)$. Even though the contribution of dysregulated Pg expression to thyrocyte transformation and thyroid carcinoma progression is unknown at present, studies in differentiated and anaplastic thyroid carcinoma tissues $(11,14,42)$ and in cell culture models $(10,12,13)$ demonstrated frequent loss of $\mathrm{Pg}$, in part along with de-differentiation. Mechanisms are mostly unknown so far and could include gene mutations/deletions, altered RNA or protein stability, hormonal dysregulation, loss/overexpression of transcriptional regulators and epigenetic silencing. This study addressed the latter two mechanisms. First, comparison of reporter-gene activity in different cell lines (cf. Fig. 2C) shows no obvious correlation to the endogenous $\mathrm{Pg}$ levels, making it unlikely that lack of essential transcription factors plays a role. The data indicate that a silencing element may reside in the first 360 nucleotides of the promoter. In addition, a putative binding site for MyoD (position -375) might be shared by the transcription factor Snail, that has recently been shown to down-regulate E-cadherin expression in tumour cells $(43,44)$ and may in another cellular context be involved in Pg gene regulation. Second, in accordance with previous investigations $(10,12)$ AzaC-mediated DNA demethylation leads to partial restoration of $\mathrm{Pg}$ expression in Pgnegative thyroid carcinoma cell lines. The cloning of the $\mathrm{Pg}$ promotor region enabled us to identify an associated CpG island, and to demonstrate by methylation-specific PCR that Pg gene methylation around the 
start point of transcription is involved in $\mathrm{Pg}$ gene silencing in thyroid carcinoma cell lines. This is the first report concerning epigenetic regulation of the $\mathrm{Pg}$ gene. Whether these mechanisms are involved in the downregulation of the $\mathrm{Pg}$ gene expression during tumour formation in the thyroid, as was shown for the Ecadherin gene (45), has to be investigated in future studies analysing thyroid tumour biopsies.

In summary, we have cloned the $5^{\prime}$-flanking region of the human $\mathrm{Pg}$ gene, characterized its promoter activity in thyroid cell lines and have identified promoter hypermethylation as a mechanism that participates to Pg expression. Further work is required to define the interaction of suggested factors contributing to the regulation of this important gene as well as a detailed analysis of the methylation pattern in carcinoma tissues, which will assist in tumour profiling.

\section{Acknowledgements}

We are grateful to Drs P Goretzki, N E Heldin and S Jhiang for the generous gifts of the cell lines. This work was supported by Deutsche Krebshilfe.

\section{References}

1 Peifer M, Berg S \& Reynolds AB. A repeating amino acid motif shared by proteins with diverse cellular roles. Cell 199476 789791.

2 Cowin P, Kapprell HP, Franke WW, Tamkun J \& Hynes RO. Plakoglobin: a protein common to different kinds of intercellular adhering junctions. Cell 198646 1063-1073.

3 Franke WW, Goldschmidt MD, Zimbelmann R, Mueller HM, Schiller DL \& Cowin P. Molecular cloning and amino acid sequence of human plakoglobin, the common junctional plaque protein. PNAS 198986 4027-4031.

4 Potter E, Bergwitz C \& Brabant G. The cadherin-catenin system: implications for growth and differentiation of endocrine tissues. Endocrine Reviews 199920 207-239.

5 Kowalczyk AP, Bornslaeger EA, Norvell SM, Palka HL \& Green KJ. Desmosomes: intercellular adhesive junctions specialized for attachment of intermediate filaments. International Reviews of Cytology 1999185 237-302.

6 Ruiz P, Brinkmann V, Ledermann B, Behrend M, Grund C, Thalhammer $\mathrm{C}$ et al. Targeted mutation of plakoglobin in mice reveals essential functions of desmosomes in the embryonic heart. Journal of Cell Biology 1996135 215-225.

7 Bierkamp C, McLaughlin KJ, Schwarz H, Huber O \& Kemler R. Embryonic heart and skin defects in mice lacking plakoglobin. Developmental Biology 1996180 780-785.

8 McKoy G, Protonotarios N, Crosby A, Tsatsopoulou A, Anastasakis A, Coonar A et al. Identification of a deletion in plakoglobin in arrhythmogenic right ventricular cardiomyopathy with palmoplantar keratoderma and woolly hair (Naxos disease). Lancet $20003552119-2124$.

9 Whittock NV, Eady RA \& McGrath JA. Genomic organization and amplification of the human plakoglobin gene (JUP). Experimental Dermatology 20009 323-326.

10 Potter E, Oster H, Mayr B \& Brabant G. DNA hypermethylation is involved in altered expression of cell adhesion molecules of the Ecadherin/catenin system in human thyroid carcinoma cells. Journal of Endocrinological Investigestion (S5) 19972079.

11 Cerrato A, Fulciniti F, Avallone A, Benincasa G, Palombini L \& Grieco M. Beta- and gamma-catenin expression in thyroid carcinomas. Journal of Pathology 1998185 267-272.
12 Husmark J, Heldin NE \& Nilsson M. N-cadherin-mediated adhesion and aberrant catenin expression in anaplastic thyroidcarcinoma cell lines. International Journal of Cancer $199983692-$ 699.

13 Celetti A, Garbi C, Consales C, Cerrato A, Greco D, Mele E et al. Analysis of cadherin/catenin complexes in transformed thyroid epithelial cells: modulation by beta 1 integrin subunit. European Journal of Cell Biology 200079 583-593.

14 Bohm J, Niskanen L, Kiraly K, Kellokoski J, Eskelinen M, Hollmen $\mathrm{S}$ et al. Expression and prognostic value of alpha-, beta-, and gamma-catenins indifferentiated thyroid carcinoma. Journal of Clinical Endocrinology and Metabolism 200085 48064811.

15 Pearson WR \& Lipman DJ. Improved tools for biological sequence comparison. PNAS 198885 2444-2448.

16 Quandt K, Frech K, Karas H, Wingender E \& Werner T. MatInd and MatInspector: new fast and versatile tools for detection of consensus matches in nucleotide sequence data. Nucleic Acids Research 199523 4878-4884.

17 Kondrakhin YV, Kel AE, Kolchanov NA, Romashchenko AG \& Milanesi L. Eukaryotic promoter recognition by binding sites for transcription factors. Computer Applications in the Biosciences $199511477-488$.

18 Heinemeyer T, Chen X, Karas H, Kel AE, Kel OV, Liebich I et al. Expanding the TRANSFAC database towards an expert system of regulatory molecular mechanisms. Nucleic Acids Research 1999 27 318-322.

19 Frohman MA, Dush MK \& Martin GR. Rapid production of fulllength cDNAs from rare transcripts: amplification using a single gene-specific oligonucleotide primer. PNAS $1988 \mathbf{8 5} 8998-9002$.

20 Goretzki PE, Frilling A, Simon D \& Röher HD. Growth regulation of normal thyroids and thyroid tumors in man. Recent Results in Cancer Research 1990118 48-63.

21 Heldin NE, Gustavsson B, Claesson-Welsh L, Hammacher A, Mark J, Heldin $\mathrm{CH}$ et al. Aberrant expression of receptors for platelet-derived growth factor in an anaplastic thyroid carcinoma cell line. PNAS $1988 \mathbf{8 5} 9302-9306$.

22 Ishizaka Y, Itoh F, Tahira T, Ikeda I, Ogura T, Sugimura T et al. Presence of aberrant transcripts of ret proto-oncogene in a human papillary thyroid carcinoma cell line. Japanese Journal of Cancer Research 198980 1149-1152.

23 Ito T, Seyama T, Hayashi Y, Hayashi T, Dohi K, Mizuno T et al. Establishment of two thyroid carcinoma cell lines $(8305 \mathrm{C}$, 8505C) bearing p53 mutations. International Journal of Oncology $19944583-586$.

24 Herman JG, Graff JR, Myohanen S, Nelkin BD \& Baylin SB. Methylation-specific PCR: a novel PCR assay for methylation status of CpG islands. PNAS 199693 9821-9826.

25 Lehmann U, Hasemeier B, Lilischkis R \& Kreipe H. Quantitative analysis of promoter hypermethylation in laser-microdissected archival specimens. Laboratory Investigation 2001 81 635-638.

26 Laemmli UK. Cleavage of structural proteins during the assembly of the head of bacteriophage T4. Nature 1970227 680-685.

27 Lowry OH, Rosebrough NJ, Farr AL \& Randall RJ. Protein measurements with the Folin phenol reagent. Journal of Biological Chemistry 1951193 265-275.

28 Towbin H, Staehelin T \& Gordon J. Electrophoretic transfer of proteins from polyacrylamide gels to nitrocellulose sheets: procedure and some applications. PNAS 197976 4350-4354.

29 Gardiner-Garden M \& Frommer M. CpG islands in vertebrate genomes. Journal of Molecular Biology 1987196 261-282.

30 Mantovani R. A survey of 178 NF-Y binding CCAAT boxes. Nucleic Acids Research 199826 1135-1143.

31 Bucher P. Weight matrix descriptions of four eukaryotic RNA polymerase II promoter elements derived from 502 unrelated promoter sequences. Journal of Molecular Biology 1990212 $563-578$.

32 Santi DV, Norment A \& Garrett CE. Covalent bond formation between a DNA-cytosine methyltransferase and DNA containing 5-azacytosine. PNAS 198481 6993-6997. 
33 Aberle H, Bierkamp C, Torchard D, Serova O, Wagner T, Natt E et al. The human plakoglobin gene localizes on chromosome 17 q21 and is subjected to loss of heterozygosity in breast and ovarian cancers. PNAS $1995926384-6388$.

34 Nollet F, Berx G, Molemans F \& van Roy F. Genomic organization of the human beta-catenin gene (CTNNB1). Genomics 199632 413-424.

35 Komuro I \& Izumo S. Csx: a murine homeobox-containing gene specifically expressed in the developing heart. PNAS $1993 \mathbf{9 0}$ 8145-8149.

36 Schott JJ, Benson DW, Basson CT, Pease W, Silberbach GM, Moak JP et al. Congenital heart disease caused by mutations in the transcription factor NKX2-5. Science $1998 \mathbf{2 8 1} 108-111$.

37 Sommers CL, Gelmann EP, Kemler R, Cowin P \& Byers SW. Alterations in beta-catenin phosphorylation and plakoglobin expression in human breast cancer cells. Cancer Research 1994 54 3544-3552.

38 Navarro P, Lozano E \& Cano A. Expression of E- or P-cadherin is not sufficient to modify the morphology and the tumorigenic behavior of murine spindle carcinoma cells. Possible involvement of plakoglobin. Journal of Cell Science $1993 \mathbf{1 0 5} 923-934$.

39 Simcha I, Geiger B, Yehuda-Levenberg S, Salomon D \& BenZe'ev A. Suppression of tumorigenicity by plakoglobin: an augmenting effect of N-cadherin. Journal of Cell Biology 1996 133 199-209.
40 Charpentier E, Lavker RM, Acquista E \& Cowin P. Plakoglobin suppresses epithelial proliferation and hair growth in vivo. Journal of Cell Biology 2000149 503-520.

41 Behrens J. Cadherins and catenins: role in signal transduction and tumor progression. Cancer and Metastasis Reviews 199918 15-30.

42 Huang SH, Wu JC, Chang KJ, Liaw KY \& Wang SM. Expression of the cadherin-catenin complex in well-differentiated human thyroid neoplastic tissue. Thyroid 19999 1095-1103.

43 Cano A, Perez-Moreno MA, Rodrigo I, Locascio A, Blanco MJ, del Barrio MG et al. The transcription factor snail controls epithelialmesenchymal transitions by repressing E-cadherin expression. Nature Cell Biology 20002 76-83.

44 Batlle E, Sancho E, Franci C, Dominguez D, Monfar M, Baulida J et al. The transcription factor snail is a repressor of E-cadherin gene expression in epithelial tumour cells. Nature Cell Biology $2000284-89$.

45 Graff JR, Greenberg VE, Herman JG, Westra WH, Boghaert ER, Ain $\mathrm{KB}$ et al. Distinct patterns of E-cadherin $\mathrm{CpG}$ island methylation in papillary, follicular, Hurthle's cell, and poorly differentiated human thyroid carcinoma. Cancer Research 1998 58 2063-2066

Received 7 June 2001

Accepted 28 June 2001 